NEWER ASPECTS OF THE PATHOLOGY OF INSANITY. 667

Generalised and Extensive Type of Onset.

The chronic alcoholic exhibits among the early recognisable symptoms, the following seven main groups:-

Generalised and extensive symptoms-complex.

First. Diminished power of recollection (amnesia), i.e., of re-vivifying past mental images or ideas.

Second. Diminished power of attention and volition, i.e., in sensorial or kinæsthetic spheres, including their interconnections.

Third. Diminished initiativeness and energy in conduct (correlated to one and two).

Fourth. Diminished muscular power ; trembling (kinæsthetic sphere); muscular act (kinæsthetic centre) requiring to be reinforced by other sensory stimuli for efficient execution.

Fifth. Blunting of higher moral and ethical sense.

Sixth. Insomnia; loss of capacity for sleep and recuperation (i.e., nutritive breakdown of the whole cortical sphere).

Seventh. Serious disturbance in the balance of cortical representations of external world and empirical ego, with melancholia and suspicion, delusions of persecution, and excitement, ballucinations, vague and gloomy feelings, and other pathetic emotional states, suicidal tendencies, passing into various chronic insanities.

We shall consider these groups of symptom groups seriatim :-

\title{
Clinical Symptomatology.
}

(a) Diminished power of recollection (amnesic type). Under the law of psychogenesis we had previously noted that the power of recalling past memories-of re-visualising things seen, of re-hearing things heard, and of re-representing previous mental images - imply a highly evolved cortical (mental) organisation, and that it has behind it a nutritive law of deep significance, under which "the external logic of events is now no longer a sine quì non needed to revivify them. They arise spontaneously, they become re-called 
thoughts, memories. Thus, thoughts arise in the child's mind. The feeling of spontaneity which accompanies these thoughts gradually get built up into the distinct recognition of the ego as the empirical source and centre of such feelings" (supra p. 648.) This capacity depends upon the integrity, therefore, of the cerebral organisation in two regards, viz., (a) the integrity of the latest evolved and elaborated anatomico-physiological connections between the neurons which subserve it, and $(b)$ the high nutritive elaboration, the high "nerve tension" and capacity for spontaneous discharge of the said neurons from time to time. Though these two are not separate, yet we shall consider them separately in order to be able to apprehend more clearly the pathogenesis of amnesia. In what respect does alcohol produce changes in these, viz., first, in the anatomico-physiological connections, or "field of conjunction" between the neurons, and second, in the higher nutrition of each individual neuron.

The results of our investigation with Golgi's method shows us that definite and recognisable changes occur in each of these respects.

\section{Internal Pathology.}

Changes in the anatomico-physiological connections (or "field of conjunction") between the neurons. Since the exact nature of such connections in health has been proved indisputably by the application of Golgi's method, it remains to inquire how and to what extent these are altered or destroyed, if at all. Onr observations show that change of a very striking and unmistakable character occurs in the ultimate protoplasmic expansions and "contact-granules" situated upon them on the one hand, and in the ultimate naked fibrils (collaterals and terminals) which everywhere come into relation with such protoplasmic termini and granules on the other. Beginning with a softening and swelling of these contact granules, and also of the protoplasmic twigs on which they are situated (fig. 33), the earliest noticeable changes are a coalescence of these into 